\title{
TRANSITION FROM PSYCHIATRIC DISPENSARIES TO COMMUNITY OUTPATIENT CARE
}

\author{
E. Chkonia, TSMU, Psychiatry, Tbilisi, Georgia. \\ J. Abramishvili, Ilia State University, Mental Health, Tbilisi, Georgia.
}

\section{Objectives:}

Increasing geographical and financial accessibility for the people with mental problems is one of the most important aims of the mental health care system. The budget for mental health care in Georgia has increased by $30 \%$ from 2016 to 2019 . The great proportion $(60 \%)$ of the budget is spent on improving the outpatient services for the patients with serious mental illness (SMI).

\section{Background:}

In order to improve the efficiency of the ongoing changes and to analyze the main obstacles for the reforms, the sixteen (16) outpatient clinics have been monitored in the different regions of Georgia.

Materials and Methods:

The assessment included quantitative and qualitative approach. The assessment was carried out by using a monitoring instrument approved by the Ministry of Health. We assessed the general data of the outpatient clinics and efficacy and availability of all the services, which are defined by the state program.

\section{Results and Conclusions:}

The study reveals that accessibility and provision with the necessary medication increased. But, due to the lack of mental health professionals in the regions, such as child psychiatrists, psychiatric nurses, clinical psychologists, and social workers multidisciplinary treatment can't be carried out. Overall, we can conclude that the quality of outpatient services slightly but steadily is improving.

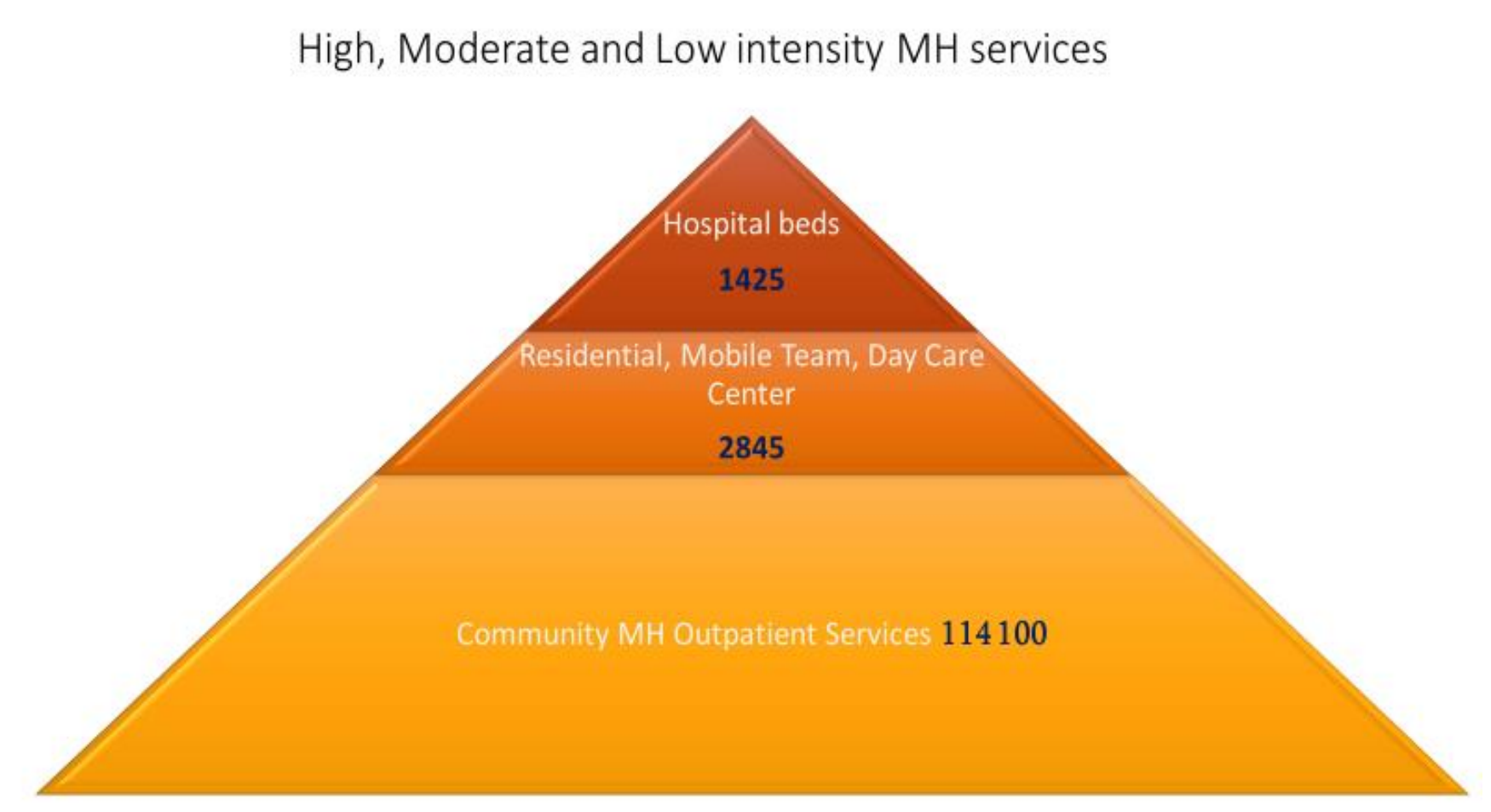

\begin{tabular}{|c|c|c|c|c|c|}
\hline \multicolumn{6}{|c|}{ State Mental Health Care program } \\
\hline \multirow[t]{2}{*}{ № } & \multirow[t]{2}{*}{ Service } & \multicolumn{4}{|c|}{ Budget in GEL } \\
\hline & & 2019 & 2018 & 2017 & \\
\hline 1 & $\begin{array}{l}\text { Community outpatient MH } \\
\text { service }\end{array}$ & 6850000,00 & 5570700,00 & 2865300,00 & $>2,4$ fold \\
\hline 2 & $\begin{array}{l}\text { Psycho-social } \\
\text { rehabilitation/day care center }\end{array}$ & 88000,00 & 77800,00 & 70100,00 & $>0,3$ \\
\hline 3 & $\begin{array}{l}\text { Child and adolescent mental } \\
\text { health community service. }\end{array}$ & 151000,00 & 151000,00 & 151000,00 & 0 \\
\hline 4 & Crises intervention service & 662300,00 & 662300,00 & 662300,00 & 0 \\
\hline 5 & Community mobile team & 1718200,00 & 774000,00 & 232200,00 & $>6,4$ fold \\
\hline 6 & MH hospital care for adults & 13660000,00 & 12793700,00 & 11479100,00 & $>0,2$ \\
\hline 7 & $\begin{array}{l}\text { MH hospital care for } \\
\text { children }\end{array}$ & 360000,00 & 350000,00 & 0,00 & \\
\hline 8 & $\begin{array}{l}\text { Shelter/Residential care for } \\
\text { patients with mental } \\
\text { disabilities. }\end{array}$ & 620500,00 & 620500,00 & 540000,00 & $>0,1$ \\
\hline & Total & 24110000,00 & 21000000,00 & 16000000,00 & $>8110000$ \\
\hline
\end{tabular}

